\title{
Recent Developments at the CMA: 2020-2021
}

\author{
Julie Bon ${ }^{1} \cdot$ San Sau Fung ${ }^{1} \cdot$ Alan Reilly $^{1,2} \cdot$ Terry Ridout $^{1} \cdot$ Robert Ryan $^{1}$. \\ Mike Walker ${ }^{1}$
}

Accepted: 21 October 2021 / Published online: 23 November 2021

(c) Crown 2021

\begin{abstract}
We discuss three important projects that economists at the Competition and Markets Authority have completed over the past year. First, our work on the Funerals Market Investigation provides an illustration of how demand-side problems can lead to a lack of competition, as well as demonstrating the CMA's willingness to consider price control and regulatory remedies where necessary. Second, on the Sabre/Farelogix merger case, we point to how our assessment dealt with uncertainty in innovative markets, the importance of preventing incumbents from acquiring start-ups, and the risks of following formalistic market definitions, especially in multi-sided platform sectors. Third, we set out the most notable developments in our revised Mergers Assessment Guidelines-including the assessment of future competition even when subject to significant uncertainty - and the assessment of the loss of dynamic competition and its effect on innovation incentives.
\end{abstract}

Keywords CMA $\cdot$ Competition policy $\cdot$ Mergers $\cdot$ Merger control $\cdot$ Competition enforcement $\cdot$ Innovation

\section{Introduction}

The Competition and Markets Authority (CMA) is the UK's primary competition and consumer protection authority and has expanded on a number of fronts in recent years.

First, we have experienced an increasing caseload; this has been driven mainly by the end of the transition period in the UK's departure from the European Union (EU) at the end of 2020. This has led to more multi-jurisdictional mergers and

San Sau Fung and Alan Reilly were formerly at Competition and Markets Authority.

Robert Ryan

robert.ryan@cma.gov.uk; ryanr5@tcd.ie

1 Competition and Markets Authority, 25 Cabot Square, London E14 4QZ, United Kingdom

2 Payment Systems Regulator, 12 Endeavour Square, London E20 1JN, United Kingdom 
antitrust cases being assessed by the $\mathrm{CMA}^{1}$ — with the increased complexity and the greater need for international cooperation that comes with those changes.

Second, the CMA has been, or is in the process of being, given expanded responsibilities and powers in a number of areas: In digital markets, a new Digital Markets Unit is already being set up, although in 'shadow' form pending the relevant legislation. As a result of the UK's departure from the EU, the government recently introduced a bill to designate the CMA as the UK's subsidy control body (replacing the EU's State Aid regime as it applied to the UK). Finally, the CMA had already set up a new Office of the Internal Market, in anticipation of Parliament's assigning the CMA a new role of monitoring the functioning of the UK internal market.

Third, unsurprisingly, the CMA's workforce has expanded to meet the increased caseload and now includes more than 100 economists, as well as a large team of data scientists, an expanded team of statisticians and market researchers, and the development of a behavioural insights team.

Before we turn to the three projects that are set out in detail below, it is worth pointing to one of the CMA's litigation successes this year, in a long-running antitrust case with substantial economic analysis: In the Paroxetine ('pay-for-delay') case, the Competition Appeal Tribunal (the UK's specialist competition court) upheld the CMA's 2016 infringement decision that found that GlaxoSmithKlinethe supplier of branded paroxetine (an anti-depressant medicine)_agreed to make payments to suppliers of generic versions of paroxetine as part of agreements that included terms that prohibited those suppliers' independent entry into the UK market. $^{2}$ The CMA found that these agreements deferred the competition that the threat of independent generic entry could offer, which potentially deprived the National Health Service of the significant price decreases that generally result from generic competition: In this case, when independent generic entry eventually did take place, average prices dropped by over $70 \%$. This judgment came after a 5-week hearing in 2017, where expert economic evidence played a key role in the proceedings: including in relation to market definition and potential entry, and on the extent to which the agreements in question resulted in any price or quality effects in the market. ${ }^{3}$

Turning to the three projects that are set out in detail in this article, we briefly point to some of the more interesting issues that are detailed in the following sections:

Our work in the funerals sector provides an illustration of how demand-side problems — in particular a lack of consumer search and price sensitivity—can lead

\footnotetext{
${ }^{1}$ For example, the AMD/Xilinx, Cargotec/Konecranes and IHS Markit/CME mergers were assessed by both the CMA and the European Commission in recent months, while, on the antitrust side, the CMA has investigated a joint business agreement between American Airlines, Aer Lingus, British Airways, Iberia and Finnair, which was previously investigated by the European Commission in 2010.

2 Competition Appeal Tribunal (2021).

3 The CMA's case owed much to the work that was done on the 'pay for delay' inference-which has been advocated by Carl Shapiro and others-as a framework for the antitrust assessment of patent dispute settlements. See, for example, Edlin et al. (2013) and Edlin et al. (2014) and reflected in enforcement activity in the US and the EU (see, for example, the Actavis case in the US (United States Supreme Court, 2013) and the Lundbeck case in the EU (European Commission, 2013).
} 
to a lack of competition, as well as demonstrating the CMA's willingness to consider price control and regulatory remedies where other measures are unlikely to be effective.

On the Sabre/Farelogix merger case, we set out our assessment of a merger in a dynamic market, drawing particular attention to dealing with uncertainty in innovative markets, assessing firms' incentives and abilities to innovate, the importance of preventing incumbents from acquiring start-ups, and the risks of following formalistic market definitions-especially in multi-sided platform sectors.

In discussing the recent revisions to the CMA's Merger Assessment Guidelines, we point to changes in relation to market definition, the treatment of uncertainty, and the counterfactual, and point to new guidance on the assessment of potential and dynamic competition, and its implications for future merger cases.

\section{Funerals Market Investigation}

\subsection{Introduction}

The CMA started to investigate the funerals market in 2018 driven by a number of concerns that had been raised with us including the vulnerability of consumers who purchase a funeral, a lack of 'shopping around' by consumers, rising funeral costs (which fall disproportionality on those on low incomes), and a limited choice of crematoria in local areas across the UK. The CMA launched an in-depth market investigation in 2019 after our initial market study reinforced these concerns. For example, our initial market study found evidence that the essential elements of funerals that are provided by funeral directors (by 'funeral director' we mean the enterprise offering a funeral) had increased in price by $6 \%$ per year for 14 years: twice the rate of inflation. We also found that the largest private crematoria operators had implemented average price rises of between 6 and $8 \%$ each year for eight years, with some local authorities also implementing large increases in fees.

In December 2020, the CMA published the final report of its funerals market investigation (CMA, 2020a). The market investigation found that competition was not effective in the funeral services sector. This lack of effective competition has the potential to affect a large number of consumers at a particularly difficult time in their lives; in 2018 there were 616,000 deaths in the UK, 517,000 of which were 'at-need' funerals. ${ }^{4}$ The total annual spend in the UK on funerals is around $£ 2$ billion. A study by Royal London (an insurance company) found that households spend, on average, around $£ 3,800$ on a funeral. The study found that the average spend on a funeral by households in different income groups does not vary significantly. ${ }^{5}$ As such, the poorest are disproportionality affected by funeral costs.

There are a number of reasons why we found that competition was not effective in the funeral services sector: First, consumer engagement is low. Few consumers

\footnotetext{
${ }^{4}$ Our investigation focused on 'at need' funerals. An 'at need' funeral is one in which the funeral was paid for at the time of bereavement, rather than through the redemption of a pre-paid plan.

5 Royal London (2019).
} 
compare between funeral directors or between crematoria, and they often have to make decisions when vulnerable and under challenging circumstances. Second, there is a lack of information available to consumers, including on price and quality (and in relation to quality, consumers cannot observe certain aspects of the quality of service that is provided to them). Finally, there is a high degree of concentration in relation to the provision of crematoria services in the vast majority of local areas, and barriers to entry are high.

We do not attempt to report on all of the issues that are covered by the market investigation here. We focus on the following areas of analysis: First, we describe our analysis of how the unique circumstances of organising a funeral affect consumers' decision-making. This analysis draws on an academic literature review that was commissioned by the CMA, as well as our own qualitative and quantitative research. Second, we describe our analysis of competition between funeral directors. This explains the weak competition between funeral directors-even though, on the supply side, across the UK there is generally a relatively wide choice of alternative funeral directors locally. Third, we considered arguments that, although each local area may be characterised by a limited number of rival crematoria, crematoria operators competed to attract marginal consumers to use their crematorium, and the competition for these consumers ensured competitive outcomes for all consumers. Finally, we describe the remedies that we considered during the market investigation and the impact of the COVID-19 pandemic on our consideration of remedies.

\subsection{Consumer Decision-Making}

The purchase of a funeral has been described by an industry participant as 'the ultimate distress purchase... made infrequently by inexpert, emotionally vulnerable clients under time pressure.' Our analysis considered how the nature of the purchase, the context in which the purchase is made, and vulnerability affect consumer decision-making.

Gathering evidence in relation to how consumers purchase a funeral provided some challenges given the sensitive nature of the purchase being made. Our analysis drew on quantitative and qualitative surveys (both our own ${ }^{6}$ and those that were submitted by parties to the investigation) and on testimony from experts and those working in the industry. We also commissioned a review of academic literature ${ }^{7}$ that explored three research questions: first, the nature and scale of the effect of recent grief on consumers' decision-making; second, the nature and scale of comparable emotional states on decision-making; and finally, what interventions have been used

\footnotetext{
${ }^{6}$ During the market study and market investigation the CMA commissioned two quantitative omnibus surveys from Ipsos MORI and one piece of qualitative research from Research Works. The qualitative research was based on 100 interviews with consumers who had each recently organised a funeral. The interviews used a semi-structured discussion guide to carry out the interviews, to ensure that key topics (such as how the choice of funeral directors and crematoria were made) were explored, whilst giving flexibility to explore issues that were raised spontaneously by individual consumers.

7 We commissioned a Rapid Evidence Assessment (REA) from NatCen. A REA uses systematic review methods to search and critically appraise existing research within the constraints of a given timetable.
} 
to address deficits in consumer decision-making under grief or comparable emotional states.

We found that a number of contextual factors could affect consumer decisionmaking when purchasing a funeral. These were: the relationship with the deceased; time pressures; conflicting priorities (such as the need to manage household finances and support surviving relatives); a lack of experience in organising a funeral; and social pressures (in particular, the desire to 'give a good send-off'). Generally, funeral consumers are vulnerable. Although grief and bereavement can affect people's decision-making to varying degrees, for many individuals clear and rational judgments can be very difficult to make in the few days after a loved one dies.

Given the above, consumers are unable to engage effectively with the process of purchasing a funeral. The consumer decision-making process tends to involve the use of low-risk strategies to make a choice of funeral director and funeral, rather than active comparisons and choices. Funeral consumers take short-cuts in decision-making; in the process they commit to a large expense on the basis of limited information.

Our consumer research highlighted the importance of the 'home area', with decision-making being driven by a desire to arrange a 'local' funeral. Very few consumers compare between funeral directors or crematoria: Our survey found that $17 \%$ and $7 \%$ of consumers compared between two or more funeral directors and crematoria, respectively. Where consumers do compare between funeral directors or crematoria, quality is often a more important factor than price. ${ }^{8}$ Around two-fifths of consumers use a funeral director that is already known to them, either because the consumer has previously arranged a funeral with that funeral director or attended a funeral that was organised by that funeral director. Otherwise, consumers tend to learn about the funeral director that they use through a personal recommendation or by word-ofmouth. In relation to crematoria, less than half of consumers considered that they had a choice of crematorium in their local area.

\subsection{Competition Between Funeral Directors}

Generally, across the UK, consumers have a choice of funeral director. There are around 7,000 funeral director branches that are operated by a wide range of providers. They encompass: national funeral director chains such as Dignity and Co-op (which, between them, account for approximately $30 \%$ of all funeral director branches); ten independent co-operative societies (which account for approximately $6 \%$ of all funeral director branches) and regional funeral directors (the largest six of

\footnotetext{
${ }^{8}$ Our survey found that in relation to funeral directors, where the use of a particular funeral director was not pre-determined by the deceased, only $3 \%$ of respondents said that value for money was the most important factor in their choice of funeral director and only $2 \%$ said that price was the most important factor in their choice. In relation to crematoria, only $1 \%$ of respondents said that value for money was the most important factor in their choice of crematorium, and no respondents said that price was the most important factor.
} 
which account for approximately $3 \%$ of all funeral director branches) — as well as a long tail of single-branch funeral directors.

Our analysis found that $93 \%$ of funeral directors have four or more rival funeral directors ${ }^{9}$ within a 15 -min drive-time. Furthermore, we found that barriers to entry in funeral directing are low, with new entrants able to hire services and facilities (such as ceremonial vehicles and refrigeration) that would otherwise require relatively high initial investment until they are established. In addition, funeral directors do not operate under any profession-specific regulation and therefore do not require any qualifications, registrations, or training before they start work. ${ }^{10}$

Nevertheless, despite a lack of concerns that relate to local concentration or barriers to entry, we found that competition between funeral directors was not effective. The behaviour of consumers-in particular, the lack of shopping around, reliance on recommendations, and insensitivity to price-means that funeral directors are not subject to the strong competitive pressure applied by consumers who shop around and switch (or threaten to switch). As such, the purchasing behaviour of consumers has significant implications for how funeral directors compete.

For example, we found that funeral directors often provide information on their prices, and what services are included, only relatively late in the sales process. ${ }^{11}$ Around half of the funeral director websites that we examined did not contain price information; and where it was available, it was often incomplete or unclear. On telephoning funeral directors, we found that: some did not provide pricing information; some required prompting to provide an explanation of what was included in the price; and other funeral directors provided information that appeared incomplete or potentially confusing. We also found that funeral directors tend to focus on their own services (in particular, aspects of quality that can be observed by consumers such as the condition of their premises and vehicles) and tend to focus on making sure that they are well known and visible in their local community-rather than responding to changes to the offerings of their competitors.

One trend that was highlighted to us was the growth in lower-priced funeral options such as simple funerals. ${ }^{12}$ A simple funeral is a more basic version of what consumers tend to expect from a standard funeral, providing key aspects of a funeral such as a coffin and staff for the ceremony, but not including other aspects such as limousines. A simple funeral may also place restrictions on the ability to view the

\footnotetext{
9 I.e. a funeral director branch under different ownership.

10 This is contrary to the belief of most consumers. Our survey found that $69 \%$ of UK adults believe that funeral directors must be licensed or registered to operate.

11 To gather this evidence, we commissioned a "mystery shop" from Ipsos MORI of 120 funeral director branches to find out what pricing information (if any) funeral directors provide to consumers who make an enquiry over the telephone and what pricing information was available on their websites.

12 Another trend that was highlighted was the growth in the uptake of direct cremations. We conducted a similar analysis in relation to direct cremations: a lower priced cremation that provides a cremation funeral without a service. We found that the uptake of direct cremation options is very low-despite high profile celebrities such as David Bowie recently opting for a direct cremation; and we found that due to the nature of direct cremation services - the cremation occurs without a service at a crematorium that is chosen by the direct cremation provider-there is likely a distinct group of consumers who want a direct cremation and who are not interested in other funeral products.
} 
deceased, or the timing and location of the funeral service. Between 2013 and 2018 the uptake of simple funerals at the largest funeral directors increased from below $10 \%$ to up to around 30\% - although this varies between funeral directors (and smaller funeral directors typically conducted a lower proportion of simple funerals).

There is some evidence of competition between the simple funeral packages of different funeral directors: For example, price reductions in simple funerals have led to an increased uptake of simple funerals. However, we did not consider that competition between simple funeral products was fully effective due to, for example, the low levels of consumer engagement (as was outlined above). We considered the impact of this increased uptake of simple funerals on standard funerals by considering the extent to which simple funerals constrain standard funerals.

We found that low-cost options do not appear to impose a significant constraint on standard funeral prices. The more limited range of services included in, and restrictions placed on, a simple funeral may make it an imperfect substitute for a standard funeral for many consumers. Despite the large price differentials between standard and simple funerals, simple funerals currently account for around up to $30 \%$ of the funerals that are sold at certain funeral directors. We found that simple and standard funeral pricing did not follow similar trends, nor were there strong reactions in standard funeral prices and/or volumes in response to simple funeral price changes, which indicates that consumers are not focussed on price and do not see simple funerals as a substitute for standard funerals.

\subsection{Competition Between Crematoria for Marginal Consumers}

Crematoria were traditionally operated by local authorities as a municipal facility. In recent years, as demand has increased, private operators have started to build crematoria and offer cremations. Today, around one third of crematoria in the UK are operated by private operators.

In contrast to funeral directors, we found that a combination of both demand-side and supply-side factors hindered competition with regard to crematoria. In particular, we found high levels of concentration in the vast majority of local markets and high barriers to entry. Crematoria operators can typically gain planning permission to open a new crematorium only if they are able to show that there is significant unmet local demand, and entry tends to occur on a 'first come, first served' basis: Typically the first crematorium operator that is able to gain planning permission for a given local area will be the only operator able to develop a crematorium in that area.

In addition, crematoria operators face economic barriers to entry due to the high initial sunk costs that are required to enter a given local area and the need to find a suitable area where the new crematorium will be able to conduct a sufficient volume of cremations in order to cover its fixed costs. Both these economic barriers and planning restrictions may lead to new crematoria locating relatively far from existing crematoria, but close to unmet demand. A new entrant - in order to ensure that it covers the sunk costs of entry and high fixed costs of operation - will have the incentive to avoid head-to-head competition with existing crematoria. 
Consumers rarely compare the offerings of two or more crematoria-our survey found that only $7 \%$ of consumers did so-and predominately choose a crematorium on the basis of location or family ties. ${ }^{13}$ Nevertheless, we did find that certain crematoria have a high proportion of consumers for whom there is a closer crematorium. This indicates that these consumers do not choose their closest option. Furthermore, private crematoria tended to have higher proportions of such consumers.

Given this evidence, we considered whether these consumers could be considered marginal consumers. These marginal consumers would decide which crematorium to use based on a comparison of the price and quality offerings of alternative crematoria and, as such, could drive competition between crematoria, benefitting all consumers. ${ }^{14}$ For a number of reasons we rejected this argument.

We found that all crematoria had consumers who could have chosen a closer crematorium. This was the case across crematoria operated by both private and local authority providers. Around one-third of private crematoria consumers have a closer alternative and around a fifth of local authority crematoria consumers have a closer alternative.

Those consumers who do not use their closest crematorium often used an alternative crematorium for reasons other than price or quality differentials - in particular, due to reasons of family connections. The most commonly cited reason in our survey for not choosing the closest crematorium was because it was 'not the family crematorium'; this was cited by nearly $40 \%$ of respondents. As such, we did not consider these consumers to be marginal.

We found that crematoria with higher proportions of consumers with a closer alternative were not necessarily better in terms of their relative price or quality: For example, they did not necessarily offer longer slots-which allow the mourners a longer time in the chapel for a service-compared with their rivals. Furthermore, we considered that differences between crematoria in terms of the proportion of their consumers who have a closer alternative could be driven, to some extent, by local factors such as transport networks and local identities.

We also considered the importance of consumers who have a closer alternative to the profitability of private crematoria. As noted above, a crematorium operator can only gain planning permission to open a new crematorium if it is able to show that there is significant unmet local demand. Recent planning appeals have determined that a new crematorium has to demonstrate that it will be the closest crematorium to a population of between around 140,000 and 170,000 people. We estimate that this equates to between around 1,000-1,300 cremations per year. Our analysis of profitability suggested that these volumes are higher than the volumes that are needed to break even, and crematoria that conduct these volumes earn a return in excess of their cost of capital. As such, the restrictions that are a feature of the planning

\footnotetext{
13 Our survey found that the most commonly cited reasons for choosing a crematorium were: that it is was the only local one, which was cited by $43 \%$ of consumers; that it had been used/attended before, which was cited by $36 \%$ of consumers; and the convenient journey time, which was cited by $18 \%$ of consumers.

14 Crematoria do not tend to price discriminate. Where crematoria do price discriminate, this tends to occur where a local authority crematorium charges lower cremation fees to its own residents.
} 
regime provide a degree of financial security and could therefore reduce the incentives for crematoria to compete aggressively for marginal consumers.

There was also wider evidence of weak competition between crematoria. For example, we conducted a performance-concentration analysis ${ }^{15}$ and estimated that when (private) crematoria experience a new entrant locally they respond not by cutting their prices, but by increasing their prices. To explain this, the evidence that we gathered indicated that a crematorium that experiences entry may increase its fees in order to maintain revenues-which further suggests weak competition among crematoria.

\subsection{The Remedies Process and the Impact of COVID-19}

In considering remedies, our preference, as a competition authority, is to seek to ensure that the competitive process can be improved so that it produces good outcomes for consumers in terms of price and quality. In the context of the funeral sector, we considered that remedies that focused on enhancing competition on the supply side were unlikely to be sufficient because of the fundamental weakness of the demand-side response. If consumers do not shop around and respond swiftly to different price or quality offerings, firms' incentives to compete remain muted.

As such, in order to address the issues that we identified, we initially considered a range of remedies that included a combination of enabling measures-to enable competition by removing obstacles to competition or stimulating actual or potential competition-and measures that seek to control outcomes: those that control the detrimental effects arising from the lack of effective competition that we identified. Given the demand-side issues identified, we considered that price regulation may potentially be the only effective solution, and the effect of other enabling measures would be limited. ${ }^{16}$

In relation to funeral directors, we considered a price control regime that would have set a maximum price for a 'benchmark' package: The benchmark package was broader than a simple funeral-given the low uptake of simple funerals and because our analysis indicated that simple funerals were not seen by consumers as substitutes for standard funerals. Funeral directors raised concerns with respect to how the package would be specified given the extent of differentiation between different funeral directors' offerings, and the effective enforcement of such a remedy given the large number of funeral directors.

In relation to crematoria, we likewise considered a price control regime that would have set a maximum price for a 'benchmark' cremation. Given that around

\footnotetext{
15 We tested how crematoria fees and volumes responded to the entry of another crematorium within their local area. We used a fixed effects econometric model to estimate the average effect of one additional crematorium on an incumbent's volume or fee.

16 Nevertheless, our initial remedies package included other measures such as information and transparency remedies (which we later adopted, and are described further below) and local authority procurement of funeral director services, which would have comprised a recommendation to local authorities to tender for funeral services in order to provide lower-priced, fixed-price funerals for their local residents.
} 
90\% of cremations are 'standard fee' services - cremation services with attendees during peak time slots-we considered this type of service to be an appropriate benchmark. Crematoria operators raised concerns with respect to the nature of the benchmark package or the setting of a price cap that would not allow operators to earn an acceptable return. We believed that the concerns that were raised in relation to funeral and crematoria price caps could be effectively mitigated through further analysis and consultation.

However, any further analysis and consultation was significantly impacted by the COVID-19 pandemic. The pandemic affected our consideration of remedies by creating uncertainty with respect to the future of the sector-in particular by potentially changing the nature of consumer demand in the future (due to changes in the types of services offered by funeral directors as a result of the pandemic), and by affecting the financial performance of the funeral sector. The design of an effective and proportionate price control remedy was thereby not practicable. Furthermore, the pandemic limited our ability to gather evidence from, and consult with, the sector, as well as limiting our ability to test remedies.

As such, we decided to pursue a more targeted set of remedies that we could develop under the circumstances of the COVID-19 pandemic. Our remedies package included a range of 'sunlight' remedies that were aimed at ensuring that the prices of funeral directors and crematoria operators are easily accessible-which would assist consumers who can and do shop around. Other remedies would keep the sector under scrutiny until such a time that the CMA could reconsider the sector once the uncertainty and limitations that have arisen as a result of the pandemic have subsided.

The sunlight remedies include a requirement for funeral directors and crematorium operators to disclose price information: For funeral directors, this includes an itemised list of frequently purchased products in a standardised format that must be displayed clearly at their premises and online. Crematorium operators will be required to provide information with respect to their fees and services to all funeral directors in their local area, as well as to consumers on request. Again, this information must be displayed clearly at their premises and online. The CMA Order-the new legal obligations described above, which are intended to assist funeral directors and crematorium operators to better support their customers-came into force on 16 June 2021, with funeral directors and crematorium operators expected to implement the changes required by the Order by the 16 September 2021.

The remedies that are aimed at keeping the sector under scrutiny included a recommendation that the CMA Board monitors and publishes an annual review of market outcomes and considers consulting on a future market investigation. Furthermore, we recommended that the UK Government and the devolved administrations in Wales and Northern Ireland establish inspection and registration regimes to monitor the quality of funeral director services, as a first step towards the establishment of a broader regulatory regime for funeral services. 


\subsection{Conclusion}

The funerals market investigation illustrates markets where the CMA has identified adverse effects on competition in markets with both more typical supply-side concerns - for local crematoria markets - as well as markets with a large number of suppliers where competition concerns arose due to demand-side concerns: namely local markets for both funeral directors and crematoria. The funerals market investigation also illustrates the wide range of analytical approaches that are used by the CMA during the market investigation to conduct our analysis: from more traditional analysis such as assessments of local concentration and barriers to entry through to a range of approaches to understand consumer behaviour and its effect on the competitive process. Finally, the initial remedies package that was proposed by the CMA demonstrates our willingness to pursue price control and regulatory remedies where it is apparent that other remedies aimed at improving the competitive process are unlikely to be sufficient, for example, in the face of consumers having difficulties in engaging in the purchasing process.

\section{Sabre/Farelogix Merger Case}

\subsection{Introduction}

The CMA prohibited the acquisition of Farelogix by Sabre in April 2020, two days after the US Delaware District Court quashed the attempt by the US Department of Justice to block the same merger. This section examines the CMA's economic assessment of this merger. ${ }^{17}$

In simple terms, Sabre/Farelogix is a case of an entrenched incumbent that acquires an emerging innovator. The case illustrates how the CMA undertakes forward-looking analyses and engages with the perceived uncertainties of dynamic merger assessments in practice. The CMA's findings at the time of the decision appear to be borne out by recent developments after the merger was abandoned.

In the remainder of this section, we first provide a brief overview of the economics of innovation that underpins the assessment. We then provide the relevant case background before summarising the CMA's theories of harm and findings, the analytical approach, and the evidence, as well as market developments after the parties abandoned the merger. Finally, we conclude by drawing broader lessons for dynamic merger assessments.

\footnotetext{
${ }^{17}$ See CMA (2020b) for the CMA's Final Report of its investigation of Sabre/Farelogix. Sabre appealed the CMA's decision before the UK Competition Appeal Tribunal (CAT). Sabre withdrew its challenge on the CMA's substantive lessening of competition findings shortly before the CAT hearing in November 2020; its challenges to the CMA's jurisdiction to review the merger were dismissed by the CAT in May 2021.
} 


\subsection{Economics of Competition and Innovation}

Economists have long debated the relationship between competition and innovation. ${ }^{18}$ Schumpeter famously argued that the prospect of market power spurs innovation, while Arrow showed instead that competition promotes innovation. Along the spectrum of these views, Aghion et al. (2005) found an 'inverted-U' relationship between competition and innovation.

These apparent ambiguous effects have led some to suggest that 'too much competition might be bad for innovation' - or (so the argument implies) that mergers might enhance innovation. But these claims are often misleading, because the earlier literature on innovation and market structure cannot be generalised in the merger context (Kokkoris \& Valletti, 2020), and there is considerable empirical evidence that shows that competition spurs innovation (Shapiro, 2012).

The economic logic that underpins the analysis of the innovation effects of horizontal mergers is analogous to that of price effects: Firms compete by offering more innovative (and lower price) products to customers. When two firms merge, their incentives to innovate are reduced because they will no longer risk losing customers to the other merging firm: They internalize the 'business-stealing' effects. Such effects are strongest in concentrated markets where the merging firms do not face constraints from other innovative rivals.

Of course, some mergers can enhance innovation by allowing firms to share expertise better or to appropriate the returns to investment better. However, merger efficiencies and their benefits to consumers should be evidenced in each caserather than presumed as a general economic principle.

\subsection{Case Background}

Sabre and Farelogix are providers of technology applications that allow airlines to sell flights to passengers via travel agents. They overlap horizontally in the supply of two products-distribution and merchandising solutions-but they operate different business and technological models.

Sabre serves both airlines and travel agents with its global distribution system (GDS). A GDS is a two-sided platform that allows airlines to distribute flight content to travel agents, and travel agents to book airline tickets on behalf of passengers. Sabre together with Amadeus and Travelport are the main GDSs: The three GDSs account for over $90 \%$ of flight bookings through travel agents globally. ${ }^{19}$ Sabre also supplies other IT applications to airlines including a merchandising module.

In contrast to Sabre, Farelogix serves airlines only. Its distribution application enables airlines to sell flights via multiple channels. These include sellling through the GDSs, but also bypassing the GDSs and selling directly to travel agents.

\footnotetext{
${ }^{18}$ For a summary of such debates, see, for example, Sidak et al. (2009); Shapiro (2012); Federico et al. (2020); Kokkoris and Valletti (2020).

19 This excludes 'local GDSs' in China, Japan and Russia which do not compete for travel agents outside of their home territories.
} 
Farelogix also supplies a merchandising application that allows airlines to sell ancillaries - such as extra checked luggage, seat upgrade, and meal options, etc.- - as part of the flight offering to passengers.

The proposed merger took place in an industry that is undergoing a complex modernisation process: Today GDSs use an old messaging standard that limits airlines' ability to create dynamic offers and to sell merchandising ancillaries. In response to airlines' demand, Farelogix pioneered a new standard known as "New Distribution Capability" (NDC). Farelogix's NDC-compatible merchandising and distribution applications allow airlines to exercise greater control over ways of selling flights and hence to reduce reliance on the GDSs. The growing adoption of NDC has given rise to competitive responses from GDSs-including from Sabre-as we explain below. $^{20}$

\subsection{CMA's Assessments}

All merger assessments entail addressing one core question: How would a merger affect competition relative to a world without the merger? Finding the right evidence to answer this question can be challenging in dynamic markets. This section first summarises the CMA's theories of harm and findings, and then discusses the analytical approach and evidence that was used in the assessment of Sabre/Farelogix. ${ }^{21}$

\subsubsection{Theories of Harm and Findings}

The CMA found that the merger would give rise to a substantial lessening of competition based on two interlinked horizontal unilateral theories of harm: The first theory relates to the supply of merchandising applications. In this market, Farelogix enjoys a 'best-in-class' reputation, and its product is used by some of the largest airlines in the world. Amadeus is another significant competitor. By contrast, Sabre lagged far behind Farelogix and Amadeus. The CMA was concerned that, despite Sabre's very small market share, it had a strong incentive to develop a new merchandising solution to meet airlines' demand; and absent the merger, Sabre would expand and become one of the three significant competitors alongside Farelogix and Amadeus. Put differently: Had Sabre acquired Farelogix, it would have abandoned its organic growth effort, and this would have reduced the number of significant competitors in the future from three to two.

Some commentators described such a concern as a 'reverse killer acquisition'. ${ }^{22}$ In contrast to a so-called 'killer acquisition' whereby an acquirer eliminates the target's pipeline products, ${ }^{23}$ in a 'reverse killer acquisition' an acquirer eliminates its own pipeline products. To elaborate on this using the current case: Sabre faced a choice between 'buy or build' to achieve its merchandising expansion. Sabre could

\footnotetext{
${ }^{20}$ Further details about the airline industry background can be found in CMA (2020b, ch. 7).

21 The CMA's reasoning and evidence are explained in detail in CMA (2020b, ch. 11).

${ }^{22}$ Caffarra et al. (2020), Latham et al. (2020).

23 Cunningham et al. (2021).
} 
simply buy Farelogix's capability through a merger and adopt its product. Had it done so, Sabre would have avoided the need to build its own products in response to customer demand and to the competitive threat posed by Farelogix. The merger would therefore 'kill' the organic innovations by the acquirer: Sabre. ${ }^{24}$

The second theory of harm concerns the supply of distribution applications. In this market, Sabre has a long-established position as one of the three main GDSs, while Farelogix's distribution product is dwarfed by the GDSs. Despite this, the CMA found that Farelogix was gaining traction with airlines and posed a direct threat to Sabre. Moreover, Farelogix's threat was reinforced by its strong merchandising product, which complements its distribution product in allowing airlines to sell dynamic flight offers to passengers. Farelogix therefore posed a double threat to Sabre in both merchandising and distribution markets. The CMA concluded that Farelogix's competitive threats would have been lost had the merger proceeded, and that although Farelogix was a smaller and differentiated competitor from the GDSs, it could have a significant impact in this concentrated distribution market.

The remainder of this section focuses on the merchandising theory of harm and explains its linkages with the distribution theory of harm where appropriate.

\subsubsection{Analytical Approach and Evidence}

The key challenge in Sabre/Farelogix was to predict how the airline industry and the parties' behaviour would evolve in a hypothetical future world if the merger did not proceed: the "counterfactuals". To do this, the CMA mainly relied on qualitative evidence to obtain insights into the commercial reality of the merging parties and the industry. This included hundreds of the parties' documents on business strategy, competitive monitoring, investment appraisal, and transaction valuation; and there were similar documents from their competitors and customers, as well as feedback from tens of market participants with direct knowledge of the demand requirements and industry trends. ${ }^{25}$

Armed with such extensive evidence, the CMA adopted an 'incentive and ability' framework and showed that absent the merger: Sabre would innovate and expand in merchandising significantly; that Farelogix's competition would continue to drive Sabre and others to innovate; and that other future constraints would be insufficient to prevent harm to competition.

Understanding the economic incentive of a firm is a crucial step in predicting its behaviour. The CMA found that Sabre had a strategic incentive to expand in merchandising not only to capture growth opportunities in this product, but also to mitigate the risk of losing value in its GDS (distribution) business. This is intuitive within the following industry context:

\footnotetext{
${ }^{24}$ Other cases in which the CMA considered similar theories of harm include PayPal/iZettle (2018); Illumina/PacBio (2020); Amazon/Deliveroo (2020).

25 See CMA (2020b, paragraphs 11.14-11.31), for an overview of all of the evidence that was assessed by the CMA in this case. The CMA set out such evidence in a final report and appendices of well over 700 pages altogether.
} 
First, airlines were seeking alternatives to the GDSs to create dynamic and personalised flight offers to passengers. Traditionally, GDSs such as Sabre perform two functions for airlines: They create flight offers, and distribute them to travel agents. However, GDSs were less flexible than the options that were available to airlines when they sell on their own websites: e.g., to change prices in real-time; to include various merchandising ancillaries; or to personalise offers to passengers. The CMA's analyses of airlines' strategy documents and other submissions revealed that a growing number of airlines were adopting NDC (which Farelogix had provided): a new standard which enables them to gain more control over the offer-creation function from the GDSs, and to realise revenue opportunities in merchandising. ${ }^{26}$

Second, Sabre lagged behind its competitors in meeting these airline demands. Farelogix, with its NDC-compatible merchandising and distribution solutions, has made inroads with airlines and allowed them to create and distribute dynamic and flexible offers to travel agents. In particular, Farelogix's merchandising solution is used by some of the largest airlines in the world; is widely perceived by customers and competitors as innovative and 'best-in-class'; and is evaluated favourably when airlines tender for suppliers of merchandising solutions. Another GDS (Amadeus) has also adopted NDC and developed an NDC-compatible merchandising product ahead of Sabre. As Sabre's distribution (GDS) and merchandising solutions were not NDC-compatible, its businesses in both markets were under threat.

The industry trends that were described above meant that Sabre had a strong incentive to catch up and upgrade its products, so as to avoid missing merchandising growth and losing value in its distribution business. Indeed, Sabre's strategy documents confirmed its intention to expand in merchandising. While specific details remain confidential to the parties, these documents generally showed that Sabre perceived Farelogix as one of its two key competitors (along with Amadeus) when developing its merchandising and wider NDC strategy. ${ }^{27}$ This provides real-world evidence of competition driving a firm to innovate and allowed the CMA to dismiss the abstract and theoretical notion that 'too much competition might be bad for innovation'.

The CMA also found that Sabre's incentive to develop a new merchandising product was backed up by its ability to do so. A range of Sabre's investment strategies and planning documents showed that, before the merger, Sabre had been investing heavily in broader NDC solutions-including merchandising components-and it had already made proposals to some airlines. ${ }^{28}$ These actions demonstrated Sabre's ability and confidence to expand. Taking this together with Sabre's strong incentive and its track record in delivering flight applications to airlines generally, the CMA concluded that Sabre would be likely to introduce a new merchandising product and become a significant competitor within three to five years.

Similarly, the CMA analysed Farelogix's likely growth trajectory and found that it would have the ability and incentive to compete strongly as an independent

\footnotetext{
26 See CMA (2020b, paragraphs 10.75-10.78; Appendix F).

27 CMA (2020b, paras 9.78-9.81).

28 CMA (2020b, paras 11.46-11.47).
} 
firm. ${ }^{29}$ This is based on Farelogix's continued success in winning and retaining contracts, its strong reputation among market participants, and its independent business model that is valued by customers in both merchandising and distribution markets. The CMA also assessed the parties' valuation models, which projected continued revenue growth for Farelogix. All these assessments enabled the CMA to dismiss the parties' contention that Farelogix would face challenges to scale up without this merger.

In addition to assessing the growth potential of the merging parties, the CMA used a consistent approach to analyse the potential for competitors to expand and constrain the parties. ${ }^{30}$ Beyond considering representations that were made by competitors and customers, the CMA examined internal documents on the competitive strategies and growth plans of all of the major competitors and found that none of them-other than Amadeus - had a combination of the ability and the incentive that was comparable to those of Sabre to expand in the merchandising market. Moreover, competitors' internal assessments of the competitive landscape and airlines' tender evaluations confirmed that these other merchandising suppliers were generally weaker than Farelogix and Amadeus. Therefore, the CMA concluded that any future constraints from other competitors' potential expansion would not be sufficient to prevent the harm to competition that would be caused by the merger. ${ }^{31}$

\subsubsection{Initial Evaluation of Market Developments After the Merger Prohibition}

The parties abandoned the merger in May 2020 after the CMA's decision to prohibit it. This provides an interesting opportunity for us to observe and evaluate actual market developments without the merger: the merger counterfactual. As will be explained below, there are indications that the CMA's findings are being borne out in reality.

Sabre has continued to expand its merchandising offerings. In November 2020 Sabre announced its plan to launch a 'Smart Retail Engine' in 2021, which integrates Google's merchandising solution through a partnership. ${ }^{32}$ Sabre's CEO described this new product as 'essentially a Farelogix replacement', and in a more recent update, confirmed that this product was on track for rollout in Spring 2021. ${ }^{33}$ The ability for Sabre to execute this alternative expansion plan after it abandoned the merger with Farelogix — and to have done it relatively quickly_refutes the parties'

\footnotetext{
${ }^{29}$ CMA (2020b, paras 11.49-11.50; 11.56-11.60).

30 CMA (2020b, paras 11.69-11.93).

31 In PayPal/iZettle (2018), the CMA found that PayPal had the ability and incentive to expand significantly and become a stronger competitor of mobile point-of-sale (mPOS) services without the merger. While this finding is not dissimilar to that for Sabre in this case, the CMA cleared PayPal/iZettle after taking account of the evidence of the growing competitive constraints from PayPal's mPOS rivals as well as the strengths of other traditional point-of-sale service providers.

32 Sabre press release, 4 November 2020, Sabre Unveils First Product Powered by its Proprietary Sabre Travel AI TM Technology.

33 Sabre earnings calls, Q3 2020 and Q1 2021.
} 
contention during the merger investigation that a fundamental change in Sabre's market position was implausible.

Farelogix also continues to compete independently of Sabre and other GDSs. Three months after the merger was abandoned, Farelogix was acquired by Accelya: a travel technology provider that is active in adjacent markets but with no direct overlaps with Farelogix. The fact that Farelogix garnered interest from another buyer so quickly - despite the onset of the Covid-19 pandemic at the time-is hardly surprising given its strong track record and industry reputation.

Overall, our initial evaluation of the market developments shows that Sabre's and Farelogix's independent product innovations have been preserved after the CMA's intervention against their merger.

\subsection{Lessons for Dynamic Merger Assessments}

The Sabre/Farelogix case provides a real-world example that confirms the economic logic that competition drives innovation. While this case concerns a relatively old industry that is undergoing a lengthy modernisation process, many of the insights apply equally to digital markets in which future dynamics are said to be uncertain. In particular, the case challenged some common contentions that have been put forward by parties and their advisers seeking regulatory approvals of dynamic mergers.

The most common, but in our view incorrect, contention is that competition authorities should refrain from intervening in dynamic mergers because of the uncertainties involved. ${ }^{34}$ The Sabre/Farelogix case shows that the CMA was able to manage such uncertainties and make reasonable predictions about counterfactuals. It is normal for companies and their investors to make decisions under uncertainties, and competition authorities can adopt a similar mindset to seek evidence and mitigate uncertainties - rather than defaulting to a clearance decision.

In this regard, company internal documents can tell us a great deal about the incentives and the ability of companies to innovate. In our experience, most businesses appraise their investment cases by asking questions such as: What are the industry trends? What do customers need? What threats are the companies responding to? What financial resources and technical capabilities do they need? How can they obtain such capabilities?

These are the same economic questions that assist in predicting business behaviour, and that competition authorities should — and can-address in dynamic merger assessments. Overall, while the CMA's evidence base in Sabre/Farelogix was largely qualitative, this does not undermine the robustness of its findings: because they are grounded in the realities of the business and the industry.

Another misconceived argument is that competition authorities should not intervene in acquisitions of 'start-up' firms because these firms are uncertain to succeed. Such a view misses the broader harm that a merger may have on the competitive

\footnotetext{
34 Walker (2020) discussed the need for competition authorities to take more account of dynamic theories of harm, more forward looking about counterfactuals, and to accept more uncertainty in merger assessments in digital markets.
} 
process itself. The presence of an emerging credible threat can constantly drive other companies to innovate, as Farelogix does to Sabre and other competitors. ${ }^{35}$ By eliminating a significant threat from the market, the acquisition of a start-up by an incumbent can cause an immediate and predictable harm to the competitive process even while the likelihood of an eventual success of that start-up remains uncertain. ${ }^{36}$

Efficiencies are another common justification that is put forward by parties that are acquiring start-up firms. For example, it is often argued that a resourceful acquirer can accelerate the growth of a start-up, or that the acquirer can draw on a start-up's talents to improve its products ('acquihire'). While these synergies may exist, competition authorities should question whether they can arise only through a merger and who would benefit from them. As occurred after the Sabre/Farelogix merger was abandoned, Farelogix was acquired by another company, and Sabre announced its new merchandising product through a partnership with Google.

These developments show that companies can use various means other than merging with a competitor to expand their capabilities. In the Sabre/Farelogix case, the benefits to consumers of preserving the competitive process-the variety of innovations and product choice — are likely to outweigh any synergies from a merger that might have primarily benefited the merging firms.

Finally, the Sabre/Farelogix case highlights the importance of understanding sources of competitive constraints over formalistic market definitions in merger assessments. Market definition appears to have played an important role in the US District Court's decision to rule in Sabre's favour in this case because, among other reasons, the court decided that Sabre's two-sided GDS platform did not compete with Farelogix's one-sided distribution product in a relevant market under US antitrust law. ${ }^{37}$ In contrast, the CMA's framework allowed it to put emphasis on assessing competitive constraints irrespective of whether the parties operate in one-sided or two-sided antitrust markets. ${ }^{38}$ Indeed, as will be discussed in Sect. 4 below, the CMA's revised Merger Assessment Guidelines now anticipate a growing emphasis on competitive assessment over static market definition, which is particularly important in dynamic industries where product features and customer demands are evolving and being shaped by the competitive process itself.

\footnotetext{
35 Facebook/Instagram provides another example of an incumbent firm responding to an emerging competitive threat, in that case, through acquiring the company. According to Facebook internal email exchanges that were revealed in the US House Antitrust Subcommittee's hearing, Facebook CEO Mark Zuckerberg took the view that 'if [Instagram] grow to a large scale they could be very disruptive' and accordingly Facebook's acquisition of Instagram was driven by both the intention to 'neutralize a potential competitor' and to integrate Instagram's products with Facebook's. See https://judiciary.house.gov/ uploadedfiles/0006322000063223.pdf.

36 This is reflected in the revised CMA Merger Assessment Guidelines, paragraph 5.20.

37 USA v. Sabre Corp. et al. Opinion of Judge Stark, 7 April 2020, page 69.

38 Hatzitaskos et al. (2021) compares the decisions of the US Delaware District Court and the CMA in Sabre/Farelogix. The authors identify market definition, structural case and presumption of harm, and the interpretation of the competitive effects evidence as the main areas of differences.
} 


\section{Revised Merger Assessment Guidelines}

\subsection{Introduction}

The CMA is the UK's primary competition and consumer authority and has sole responsibility for the implementation of merger control in the UK. In support of that function, the CMA publishes Merger Assessment Phase 2 for an in-depth investigation, where the CMA assesses whether a merger gives rise to an SLC on 'the balance of probabilities'.

In 2020, the CMA began a process of updating its MAGs in order to bring them up to date and aligned with best practice: The previous version of the MAGs had been in place for over 10 years (Office of Fair Trading, 2010); and, in the intervening years, the CMA's approach to merger control evolved by building not only on its own experience of investigating mergers, but also on the experience of: other competition authorities; recent case law; and a number of relevant expert reports and academic literature. ${ }^{39}$ Alongside these developments, the CMA also observed wider changes in the types of issues that it confronts in its assessment of mergers, including the evolution of digital technologies; and the associated impact on the types of goods and services that consumers consume and the manner in which businesses compete.

The CMA launched a public consultation on its proposed revisions to the guidance in November 2010, and finally adopted the revised MAGs in March 2021 (CMA, 2021a).

This section proceeds in two parts: First, we outline some of the significant changes that we made to the Guidelines with respect to market definition, the treatment of uncertainty, and the counterfactual. Second, we focus on the CMA's new guidance as to its assessment of losses of potential and dynamic competitionwhich represents one of the main ways in which the MAGs have been expandedand comment on some implications for the assessment of future mergers by the CMA.

\subsection{Summary of Specific Changes}

The CMA's revised MAGs contain significant updates across most aspects of merger assessment. The CMA has expanded or refined its guidance on a range of aspects of its assessment: two-sided markets; potential and dynamic competition; the 'failing firm' defence; mergers of firms that are active in many local areas; the foreclosure theories of harm; countervailing buyer power; entry and expansion; and market definition. The CMA has also provided clarity over cross-cutting issues such as the role of non-price competition, and its approach to assessing and attaching weight to different types of evidence (CMA, 2020c).

39 The CMA (2020c) sets out some of these documents in a consultation document. 
In this subsection, we comment on some changes that were made by the CMA in relation to market definition, the treatment of uncertainty, and the counterfactual.

\subsubsection{Market Definition}

In the revised MAGs, the CMA provided clarification on the role of market definition and its use as an analytical tool in merger control. The revised MAGs explain that the CMA often relies on evidence that relates to closeness of competition which 'can often be interpreted without having defined the relevant market' (CMA, 2021a). An implication of this is that the CMA could in some cases move directly to the consideration of evidence on closeness of competition-rather than conducting a market definition exercise as a separate first step.

The attraction of this approach is intuitive: Consider, for example, a case where the CMA is assessing competition between firms that supply differentiated products, where it has considered: evidence from third parties on the merging parties' closest substitutes; evidence from internal documents on competitive benchmarking; and tender data that show which firms the merging firms tended to win or lose against. Each of these may provide the CMA with evidence as to the importance of the constraint that is exerted by the merging firms on each other-without first having decided which products are 'inside' or 'outside' the market. In that context, there may be limited incremental evidentiary value to the CMA from a standalone market definition exercise.

In fact, the definition of the relevant market may flow from the competitive assessment, rather than serve as a precursor step that must take place before it:

There may be no need for the CMA's assessment of competitive effects to be based on a highly specific description of any particular market definition (including, for example, descriptions of the precise boundaries of the relevant markets and bright-line determinations of whether particular products or services fall within the relevant market). The CMA may take a simple approach to defining the market-for example, by describing the market as comprising the most important constraints on the merger firms that have been identified in the CMA's assessment of competitive effects.

This is not to say that market definition is irrelevant. In some cases, the CMA may well find it helpful to consider market definition. However, even in such cases, evidence that is considered in the CMA's competitive assessment is likely to be informative of the products that should be included or excluded-given that the CMA's assessment of competitive effects will 'often capture market dynamics more fully than formal market definition'.

\subsubsection{Treatment of Uncertainty}

The revised MAGs contain a new section that describes how the CMA ascribes weight to evidence in different contexts. In this new section, the CMA has expanded on how it interprets evidence in the context of uncertainty. For example: 
The fact that there may be some uncertainty in how the market is likely to develop in future is a relevant consideration but may not be determinative. It does not, by itself, reduce the likelihood that a merger could give rise to competition concerns, and the presence of some uncertainty therefore does not in itself preclude the CMA from finding competition concerns on the basis of all the available evidence where the CMA is satisfied that the relevant standard of proof is met.

Although merger assessments are inherently prospective, the new MAGs make clear that uncertainty does not of itself favour clearance. The implication is that-on the assumption that the CMA has been able to gather probative evidence on the likelihood of certain market developments coming to pass, and the evidence of those market developments coming to pass is more persuasive than the evidence to the contrary - the CMA may well attach weight to those market developments. The CMA will not be deterred from doing so simply because it cannot predict the market development with confidence.

\subsubsection{Counterfactual}

The CMA's updates to the MAGs clarifies its approach to assessing the counterfactual: the competitive situation that would have prevailed without the merger, and essentially the benchmark against which the CMA assesses the merger. The new MAGs indicate that the CMA's focus in establishing the counterfactual will generally be on developments that significantly affect the overall level of competition between the merger firms, which implies that more nuanced changes in competitive conditions or factors that affect third parties may be considered in the competitive assessment. The CMA will also avoid seeking to predict precise details-such as specific product characteristics_or distinguishing between different scenarios that would have the same broad impact on competition between the merging firms: either to make it stronger or weaker.

The new MAGs also signal a greater willingness to consider potential market developments that stretch some years into the future. ${ }^{40}$ The CMA makes clear that when doing so, it would also consider the potential for third-party entry and expansion and the scope for efficiencies over a similar timeframe.

The CMA also explicitly states that it will consider evidence on the ability and the incentive of the merger firms to enter or expand in competition with each other when considering the counterfactual. The implication of looking at ability and incentive is that the CMA may include entry or expansion by one or both of the merger firms in the counterfactual even absent explicit documented plans to enter, which reflects the CMA's guidance that 'the decision to pursue a merger may supplant the creation of detailed business plans assessing alternative routes to enter

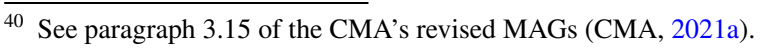


or expand.' This is consistent with other areas of the CMA's assessment where evidence on abilities and incentives are considered as a matter of course.

\subsection{Potential and Dynamic Competition}

One important addition to the MAGs has been a significant expansion in the guidance provided by the CMA on its approach to the assessment of losses of potential and dynamic competition. This addition by the CMA reflects the growing importance of digital markets and platforms, where the rise of new platforms may be an important dynamic of competition that plays out over long periods of time, and where concerns have been raised in relation to killer acquisitions and reverse killer acquisitions. ${ }^{41}$ This subsection discusses the CMA's new guidance in relation to losses of dynamic competition and in particular: the economic reasoning behind this theory of harm; the implications for merger assessment; considerations that are relevant to the CMA's evidence and evidentiary standard; and the profile of mergers to which this theory of harm is more likely to be relevant.

In its previous guidance, the CMA's framework for considering losses of potential competition centred on two questions: "would the potential entrant be likely to enter absent the merger?"; and "Would such entry lead to greater competition?". Concerns arise where the answer to both questions is 'yes'.

This framework could be interpreted to presume that competition takes place only from some point in the future after entry or expansion has occurred. This in turn implies that entry is an exogenous event, and solely a precursor to competition, but not part of the competitive process. Under that presumption, if entry is 'unlikely', it follows that any logical consequence of that entry-including an increase in competition in the counterfactual-would also be 'unlikely'.

But this misunderstands the competitive process and could lead to an enforcement gap. Competition is the process by which firms win or retain customers by improving what they offer. However, the ways that firms win or retain customers are not limited to flexing of short-run parameters of competition. Take the pharmaceutical sector, for example. In that sector, the 'quality' of a product-encompassing its effectiveness in treating symptoms, its safety and toxicity, the convenience of its administration, and so on-has an important influence on product choice. However, that 'quality' is not easily flexed in response to competition once the treatment has been researched, trialed, and launched-at least not without conducting further research and trials. Therefore, the focus of short-run efforts to win customers naturally shifts towards aspects of the competitive offering that are more flexible in the short-run, such as price or certain other aspects of quality or service.

But does this imply that the core aspects of treatment 'quality' are not relevant aspects of competition in the pharmaceutical sector? On the contrary: The investments that are made by pharmaceutical companies in developing new, higher-quality treatments are still a fundamental means by which they win new customers. Beyond

$\overline{41}$ See, for example, the preceding section on the Sabre/Farelogix merger. 
pharmaceuticals, the efforts and investments of firms to innovate are a core means by which they compete-even if there is no short-run impact on the competitive offering that could appeal to customers.

What this example underlines is that the efforts and investments that are made towards entry or expansion should be in some cases thought of as part of the competitive process, rather than as an exogenous event that should be assessed separately purely as a precursor to competition; and a model of competition that does not fully capture this business reality may lead to the omission of some competitive effects.

\subsubsection{How Mergers Might Affect Dynamic Competition}

The CMA's updated MAGs clarify that mergers can harm this dynamic process of competition by affecting the incentives of dynamic competitors to enter or expand, or their incentive to respond to the entry or expansion of rivals. This is based on the following reasoning:

- Firms, when deciding whether to invest in new entry or expansion, choose to incur the short-run costs of investment in return for an expected long-run payoff from the profits on the eventual sales of the product. Some of these sales will come from entirely new demand, but some sales may also be 'stolen' from existing firms that are already active (or from other entrants who may enter first).

- If a firm that would have invested in entry or expansion merges with an incumbent-or with another firm that is also investing in entering or expanding at the same time- their incentive to continue to make those same investments may be reduced if the sales that they can expect to win post-entry or expansion would have been stolen from the other merging party. This is because sales that are made to customers of the other merging party may no longer represent incremental sales from the perspective of the merged entity, and firms that make investment decisions will rationally only take incremental sales into account when appraising investments. Similar reasoning is set out in Federico et al. (2020).

- Furthermore, incumbent firms may-pre-merger-have an incentive to respond to the threat of entry or expansion by rivals, because rival entry or expansion represents a threat to the future profits of the incumbent. To defend those profits, incumbent firms may have an incentive to act now to invest in improving their own future ability to compete.

The implications of this is that even two firms that are not currently substitutes for each other-for example, because one is not present in the market—can induce each other to make investments that have value to consumers. A reduction in those efforts that is brought about by a merger represents harm to competition in the present and not just at some distant point in the future. Such harm can arise even where the eventual success of a rival cannot be predicted confidently-for example, whether it would have a large effect.

The assumption that firms' investment behaviour accounts for their future sales and profits in this way reflects a much more realistic model of firm behaviour than static models that assume that firms set price and quality while considering only 
short-run profits. Just as merger control authorities are forward-looking, so too are the firms that they assess.

\subsubsection{Implications for Merger Assessment}

An important implication is that dynamic competition concerns may arise even when the likelihood of successful entry or expansion is not $50 \%$ or greater.

To return to the example of pharmaceuticals: Consider an example where one incumbent firm has the only available treatment for a rare disease, which is used to treat all patients. It merges with a firm with an in-the-pipeline treatment that has a $40 \%$ chance of being launched successfully. The incumbent is currently investing in its product by researching a less burdensome mode of administration-say, a tablet instead of an injection-which healthcare providers are not willing to pay more for, but would increase patient loyalty.

Given that there is only one existing treatment, the large majority of the pipeline treatment's eventual sales (if it is successful) will likely be 'stolen' from the incumbent. Given this, the merger would likely make investment in the pipeline treatment much less attractive. The incumbent's incentive to develop a new mode of administration may also be substantially diminished_-given that the pipeline treatment is the only real threat to its current position.

A reduction in these efforts would be a harm to dynamic competition-even though the entrant only has a $40 \%$ chance of actually selling its product in the future. However, under the traditional framework that was outlined above, the CMA could still receive arguments (from the merger's proponents) that competition was unlikely to have arisen in the counterfactual, simply because there was a less than $40 \%$ chance of the pipeline treatment actually coming to market, and that there therefore could be no substantial lessening of competition at the relevant legal standard-even in a scenario where the CMA found clear evidence that the incumbent planned to discontinue investment in the pipeline treatment immediately after completing the merger.

To accept this argument would be to ignore the point that the efforts towards entry and expansion have economic value to consumers today. By way of analogy, a consumer holding a raffle ticket with a $40 \%$ chance of winning a significant prize is better off than a consumer holding no ticket at all.

\subsubsection{Evidence}

The relevant legislation requires that the CMA must meet a 'balance of probabilities' standard in order to find that a merger gives rise to an SLC at Phase 2; this is interpreted to mean a greater than $50 \%$ likelihood based on the totality of the evidence the CMA has considered. In the context of the previous discussion, some respondents to the CMA's consultation asked the CMA to clarify that dynamic 
losses of competition would not change that legal standard. ${ }^{42}$ The CMA was clear in its response that the legal standard is not affected by this change to its MAGs. ${ }^{43}$ The implication is that the CMA must, at Phase 2, find that there is a greater than $50 \%$ likelihood that the innovation efforts of dynamic competitors would be reduced by a merger, and that such a reduction in innovation efforts amounts to a substantial lessening of competition.

A reduction in efforts towards a new product may not always constitute a substantial lessening of competition. In markets where there is already a wide range of products and where there is already plenty of existing competition, a reduction in efforts towards launching products may not be as concerning as in other markets where choice or competition is limited.

In terms of evidentiary requirements, the assessment of dynamic theories of harm will likely rely on similar evidence to that gathered for potential competition cases: evidence on the likelihood that the parties would enter or expand, and evidence on the importance of that eventual entry or expansion to consumers in the form of increased competition or range.

Some submissions that responded to the CMA's consultation suggested that dynamic losses of competition may be relevant only in cases where the CMA has identified explicit evidence that dynamic constraints are perceived as such. ${ }^{44}$ However, this would be an inappropriate bar to set. Evidence on incentives are important and valid-even in the absence of documentation that explicitly sets out the perceptions or intentions of the merging firms. To insist on the latter would create an enforcement gap with respect to firms that account for merger control risk when generating internal documents. In its new MAGs, the CMA underscores the role of incentives in its assessment-not just in relation to losses of dynamic competition but more widely:

The CMA may take into account any evidence of an explicit intention on the part of the merger firms to take a particular course of action that would be consistent with an SLC, such as raising prices, foreclosing a rival, reducing their efforts to innovate, or to enter or expand in a market absent a merger. However, there is no requirement for the CMA to find any such direct evidence of explicit intentions, and the CMA will often rely on an assessment of the firms' economic incentives.

The CMA has already considered this type of theory of harm prior to the new MAGs' publication. As was set out in the preceding section, in Sabre/Farelogix the CMA was concerned about the elimination of a threat to Sabre that would result in harm to the competitive process because of reduced incentives for Sabre to innovate to protect its future profits from Farelogix. In Illumina/Pacific Biosciences, the CMA was investigating a merger that involved two suppliers that were developing systems to sequence DNA. The CMA provisionally found: that Pacific Biosciences

\footnotetext{
${ }^{42}$ See paragraph 2.53 (c) the CMA's summary of responses to the consultation (CMA, 2021b).

43 See paragraph 2.61 in the CMA's summary of responses to the consultation (CMA, 2021b).

44 See paragraph 2.53 of the consultation document (CMA, 2020c).
} 
represented a threat to Illumina's future profits; that this was a factor that was driving Illumina's innovation efforts at the time; and that the merger would lead to a shift in R\&D away from research that they would have done absent the merger (CMA, 2019). ${ }^{45}$

\subsubsection{Relevance to Individual Mergers}

It is unlikely that dynamic theories of harm will be relevant in all cases. The above discussion points to certain circumstances where a dynamic assessment may be more or less important:

First, it may be more appropriate to consider losses of dynamic competition in sectors where long-run efforts and investments are the way that firms flex aspects of their offer that are important to consumers. In this respect it is important to note that efforts towards entry and expansion is a broad term: Examples that are listed by the CMA in the new MAGs include: investing in a brand; building up consumer loyalty; or selling at a loss to develop a reputation or build up a network of customers on a platform.

Second, losses of dynamic competition may be less relevant when the decisions by firms to enter or expand can be taken in relatively short order and are not subject to substantial uncertainty. For example, in scenarios where the decision by a retail firm to enter a new local area would lead to relatively rapid entry with relatively little uncertainty, it may be simpler to consider a merger that involves potential competitors under the traditional framework of a loss of future competition.

Third, the relevance of losses of dynamic competition will naturally depend on the importance of dynamic constraints. In some industries where there is a wide range of products and competitors, the loss of a dynamic competitor may be less likely to lead to a competition concern. However, there may be exceptions to this: for example, a scenario where a dynamic competitor threatens to disrupt an entire industry with a new business model, and the significance of this threat drives incumbent firms to make innovation efforts beyond the lesser efforts that they would make simply to keep up with incumbents.

\subsection{Conclusion}

The CMA has made a range of updates to its MAGs that touch on a wide range of aspects of its approach to merger assessment to reflect recent developments and the CMA's experience in the 10 years since its previous guidelines were published. The new MAGs provide greater clarity about the role of market definition and the potential for the CMA to place greater emphasis on a direct assessment of competitive

\footnotetext{
${ }^{45}$ See paragraphs 8.333 and 8.334 of the CMA's provisional findings on the Illumina/Pacific Biosciences case (CMA, 2019), for example. The merger between Illumina and Pacific Biosciences was abandoned following the CMA's provisional findings, and the CMA therefore did not publish a final report.
} 
effects; the ability of the CMA to consider developments of competition over the longer term-even when subject to significant uncertainty; and the potential role for losses of dynamic competition that affect innovation incentives.

\section{References}

Aghion, P., Bloom, N., Blundell, R., Griffith, R., \& Howitt, P. (2005). Competition and innovation: an inverted-U relationship. The Quarterly Journal of Economics, 120(2), 701-728. https://doi.org/10. 1093/qje/120.2.701

Caffarra, C., Crawford, G. \& Valletti, T., (2020). 'How tech rolls': Potential competition and 'reverse' killer acquisitions, VoxEU.

CMA (2019). Anticipated acquisition by Illumina, Inc. of Pacific Biosciences of California, Inc.; Provisional Findings Report. Retrieved July 20, 2021 from CMA website: Illumina Pacbio: Provisional findings report (publishing.service.gov.uk).

CMA (2020a). Funerals market investigation. Final Report, 18 December 2020: Funerals Market Investigation final report (publishing.service.gov.uk).

CMA (2020b). Anticipated acquisition by Sabre Corporation of Farelogix Inc. Final report, 9 April 2020: Sabre / Farelogix final report (publishing.service.gov.uk).

CMA (2020c). Draft revised merger assessment guidelines: Consultation document, November 2020. Retrieved July 30, 2021, from CMA website: Draft revised Merger Assessment Guidelines: Consultation (publishing.service.gov.uk).

CMA (2021a). Merger Assessment Guidelines, March 2021. Retrieved July 30, 2021, from CMA website: Merger Assessment Guidelines (CMA129) (publishing.service.gov.uk).

CMA (2021b). Revised merger assessment guidelines: Summary of response to the consultation. Retrieved July 30, 2021, from CMA website: Revised Merger Assessment Guidelines: Summary of responses to the consultation (publishing.service.gov.uk).

Competition appeal tribunal (2021), GSK and others v competition and markets authority, Supplementary Judgment [2021] CAT 9, 10 May 2021. 1251/1/12/16; 1252/1/12/16; 1253/1/12/16; 1254/1/12/16; 1255/1/12/16 Generics UK Limited; GlaxoSmithKline PLC; Xellia Pharmaceuticals APS (2) Alpharma LLC; Actavis UK Limited; Merck KGaA v Competition and Markets Authority - Judgment [2021] CAT 9। 10 May 2021 (catribunal.org.uk).

Cunningham, C., Ederer, F., \& Ma, S. (2021). Killer acquisitions. Journal of Political Economy, 129(3), 649-702.

Edlin, A., Hemphill, S., Hovenkamp, H., \& Shapiro, C. (2013). Activating actavis. Antitrust, 28(1), 16-23.

Edlin, A. S., Hemphill, S., Hovenkamp, H., \& Shapiro, C. (2014). Actavis and error costs: A reply to critics. The Antitrust Source pp.1-8.

European commission (2013), Lundbeck Decision, 19 June 2013: 39226_8310_11.pdf (europa.eu).

Federico, G., Scott Morton, F., \& Shapiro, C. (2020). Antitrust and innovation: Welcoming and protecting disruption. Innovation Policy and the Economy, 20, 125-190.

Hatzitaskos, K., Howells, B., \& Nevo, A. (2021). A tale of two sides: Sabre/farelogix in the United States and the UK. Journal of European Competition Law \& Practice. https://doi.org/10.1093/jeclap/lpab0 47

Kokkoris, I., \& Valletti, T. (2020). Innovation considerations in horizontal merger control. Journal of Competition Law \& Economics, 16(2), 220-261. https://doi.org/10.1093/joclec/nhaa008

Latham, O., Tecu, I., \& Bagaria, N. (2020). Beyond killer acquisitions: Are there more common potential competition issues in tech deals and how can these be assessed? CPI Antitrust Chronicle, 2(2), 26-37.

Office of Fair Trading and Competition Commission (2010). Merger Assessment Guidelines, September 2010. Retrieved July 30, 2021, from CMA website: https://assets.publishing.service.gov.uk/gover nment/uploads/system/uploads/attachment_data/file/284449/OFT1254.pdf.

Royal London (2019), Change on the horizon? National funeral cost index report 2019.

Shapiro, C. (2012). Competition and innovation: Did arrow hit the bull's eye? In J. Lerner \& S. Stern (Eds.), The rate and direction of inventive activity revisited (pp. 361-404). National Bureau 
of Economic Research Conference Report. University of Chicago Press. https://www.nber. org/books-and-chapters/rate-and-direction-inventive-activity-revisited/competition-and-innov ation-did-arrow-hit-bulls-eye

Sidak, J. G., \& Teece, D. J. (2009). Dynamic competition in antitrust law. Journal of Competition Law \& Economics, 5(4), 581-631. https://doi.org/10.1093/joclec/nhp024

Walker, M. (2020). Competition policy and digital platforms: Six uncontroversial propositions. European Competition Journal, 16(1), 1-10. https://doi.org/10.1080/17441056.2020.1730063

United States Supreme Court (2013). FTC vs Actavis Inc, 570 U.S. 136; 133 S. Ct. 2223.

Publisher's Note Springer Nature remains neutral with regard to jurisdictional claims in published maps and institutional affiliations. 